Agrotrópica 33(2): 117 - 126. 2021.

Centro de Pesquisas do Cacau, Ilhéus, Bahia, Brasil

\title{
TESTE DE TETRAZÓLIO EM SEMENTES DE ESPÉCIES DO DOMÍNIO FITOGEOGRÁFICO AMAZÔNICO
}

\author{
Pamela Porfirio Gonçalves, Juliana Garlet
}

\begin{abstract}
Universidade do Estado de Mato Grosso - UNEMAT, Departamento de Engenharia Florestal. Faculdade de Ciências Biológicas e Agrárias, Campus II, Perimetral Rogério Silva, s/n, Jardim Flamboyant, 78580-000, Alta Floresta (MT), Brasil.pamela.goncalves@unemat.br.julianagarlet@unemat.br
\end{abstract}

O objetivo deste trabalho foi o levantamento de dados através de pesquisas por metodologias adequadas para a aplicação do teste de tetrazólio em sementes nativas do domínio fitogeográfico amazônico. Foi realizada uma pesquisa seletiva no site Flora do Brasil (2020) por espécies nativas do Brasil e do bioma amazônico, a partir da lista que consta no documento do MAPA (Brasil, 2013). Posteriormente, realizou-se uma pesquisa exploratória de forma qualitativa em bancos de dados online do Google Acadêmico, Scielo e Scopus por artigos, dissertações, teses, trabalhos de conclusão de curso, com teste de tetrazólio para tais espécies, seguida de uma análise seletiva e analítica, compilando as metodologias indicadas nos trabalhos para a realização de testes de tetrazólio. Das 141 espécies do domínio fitogeográfico Amazônico que constam na lista no documento do MAPA, apenas para 36 foram encontrados estudos com análise de sementes utilizando tetrazólio. Assim, verificou-se que existem poucos trabalhos na literatura que fornecem informações para a aplicação do teste de tetrazólio nas espécies Amazônicas. Restringindo assim, o uso dessa análise de grande importância para os programas de controle de qualidade de sementes, evidenciando a necessidade de pesquisas que proporcionem o enquadramento dessas metodologias na RAS (Regras para Análise de Sementes).

Palavras-chave: Sementes florestais, teste de vigor, viabilidade.

Tetrazolium test in seeds of species of the amazonic phytoogeographic domain. The objective of this work was to collect data through research by appropriate methodologies for the application of the tetrazolium test in native seeds and in the Amazonian phytogeographic domain. A selective search was carried out on the Flora do Brasil website (2020) for species native to Brazil and the Amazon biome, from the list in the MAPA document (Brasil, 2013). Subsequently, an exploratory research was carried out in a qualitative way in online databases of Google Scholar, Scielo and Scopus for articles, dissertations, theses, conclusion papers, with a tetrazolium test for such species, followed by a selective analysis and analytical, compiling the methodologies indicated in the works for carrying out tetrazolium tests. Of the 141 species in the Amazonian phytogeographic domain that are listed in the MAPA document, only 36 studies with seed analysis using tetrazolium were found. Thus, it was found that there are few studies in the literature that provide information for the application of the tetrazolium test in Amazonian species, restricting the use of this analysis of great importance for seed quality control programs, highlighting the need for research that provides the framing of these methodologies in the RAS (Rules for Seed Analysis).

Key words: Forest seeds, vigor test, viability. 


\section{Introdução}

A avaliação da qualidade fisiológica das sementes é indispensável para a comercialização dos lotes. $\mathrm{O}$ teste de germinação é muito utilizado para determinar se fisiologicamente as sementes estão viáveis, porém, é um teste que requer períodos de tempo relativamente longos, principalmente em espécies que possuem germinação lenta. Portanto, os testes que avaliam de forma rápida e eficaz a viabilidade e/ou vigor das sementes, estão sendo cada vez mais estudados por serem uma ferramenta promissora em programas de controle de qualidade de sementes.

$\mathrm{O}$ controle de qualidade de sementes florestais em laboratório é realizado através de análises, cujo objetivo principal é determinar o valor das sementes de um lote após sua extração e beneficiamento, antes de serem remetidas ao viveiro ou para armazenamento (Fowler e Martins, 2001). A demanda por sementes florestais tem-se tornado maior para recuperações de áreas degradadas, recomposição de matas ciliares e reserva legal, como também para plantios com intuito de produção madeireira. Porém, ainda existe uma vasta carência de estudos em tecnologias de análises de sementes para atender essa demanda.

A RAS (Regras para Análise de Sementes) (Brasil, 2009) disponibiliza métodos oficiais para análise de pureza, peso de mil sementes, determinação do grau de umidade, teste de germinação, e para diversas outras análises, que reúnem um conjunto de técnicas, procedimentos e prescrições, que padronizam a metodologia empregada para uma dada espécie, os quais são de uso obrigatório em laboratórios credenciados pelo MAPA que realizam essas análises.

Os estudos com tecnologia de sementes atualmente, tem-se voltado em técnicas que avaliam a qualidade fisiológica de sementes com períodos de tempos mais curtos, facilitando o controle de qualidade para produção de sementes em larga escala. Os testes de embrião excisado, condutividade elétrica, raios $\mathrm{X}$, e de tetrazólio, são exemplos de testes rápidos e promissores. Mas esse estudo irá abordar metodologias para o teste de tetrazólio em espécies do bioma amazônico.

O teste de tetrazólio é utilizado para determinar a viabilidade de forma rápida e eficaz, além de apresentar resultados até em sementes com dormência, e em sementes que se encontram em estado de dureza após o teste de germinação. As metodologias estão disponíveis na RAS para determinadas espécies, e em artigos de pesquisa, porém, seu emprego ainda é muito limitado. Pois para a grande maioria das espécies em geral não existe metodologias para a realização do teste, e principalmente em espécies nativas da região amazônica.

O teste de tetrazólio é um teste bioquímico, no qual as sementes são embebidas em uma solução incolor de 2,3,5-trifenil cloreto ou brometo de tetrazólio, nas concentrações entre $0,05 \%$ a $1,0 \%$, variando para sementes de diferentes espécies, ao qual é usado como um indicador para revelar o processo de redução que acontece dentro das células vivas. Neste processo, os íons de $\mathrm{H}+$ liberados durante a respiração dos tecidos vivos são transferidos por um grupo de enzimas, particularmente, a desidrogenase do ácido málico, e interagem com o tetrazólio, o qual é reduzido a um composto vermelho, estável e não difusível chamado de trifenil formazan. Como esta reação se processa no interior das células vivas e o composto não se difunde, há nítida separação dos tecidos vivos e coloridos que respiram, daqueles mortos e que não colorem (Brasil, 2009).

A realização do teste de tetrazólio exige a aplicação de procedimentos que preparam as sementes para a coloração, tais como, o pré-umedecimento que se faz necessário para algumas espécies e altamente recomendado para outras, facilitando a absorção da solução do reagente; exposição dos tecidos do embrião para a coloração, que permite melhor absorção da solução de tetrazólio e facilita a avaliação para muitas espécies. Sendo utilizadas diferentes técnicas para expor os tecidos internos, como a perfuração e/ou escarificação mecânica da semente, corte longitudinal, corte transversal, incisão transversal, extração do embrião, e até a remoção do tegumento. $\mathrm{O}$ pH da solução deve estar entre 6,5 a 7,5, pois soluções ácidas retardam a reação, a temperatura entre $30-40^{\circ} \mathrm{C}$, não ultrapassando os $40^{\circ} \mathrm{C}$ para que não ocorra a degradação das proteínas, o armazenamento das sementes em solução de tetrazólio deve estar sob pressão nula ou desprezível, e no escuro, tornando a reação mais rápida e evitando a redução do sal, uma vez que a luz causa este efeito (Peske et al., 2006). 
O objetivo principal do teste de tetrazólio é distinguir as sementes viáveis das não viáveis. Uma avaliação cuidadosa, baseada nos padrões de coloração e de sanidade dos tecidos, torna possível separar diferentes categorias de sementes dentro desses dois grupos (Brasil, 2009). As sementes consideradas viáveis colorem completamente, como também parcialmente, desde que apresente padrões de coloração que indiquem a viabilidade, e as sementes não viáveis não colorem ou não possuem coloração bem definida.

As informações sobre o teste de tetrazólio em sementes de espécies nativas da Amazônia são escassas e estão dispersas em diversos artigos científicos, diante disto, essa pesquisa teve por objetivo reunir todas essas informações neste artigo, com o intuito de facilitar a procura do material por estudantes e pesquisadores.

\section{Material e Métodos}

Esta pesquisa trata-se de uma revisão bibliográfica, não sistematizada, classificada como exploratória de forma qualitativa, realizada por meio de levantamentos bibliográficos em periódicos científicos, nos idiomas português e inglês. A lista de espécies utilizada para realizar a pesquisa consta no documento do MAPA (Brasil, 2013). Tais espécies foram consultadas no site da Flora do Brasil (2020), com o objetivo de buscar por espécies nativas do Brasil e do domínio fitogeográfico da Amazônia.

Com base nesses resultados, foi pesquisado em bancos de dados online do Google Acadêmico e Scielo, por artigos científicos com informações de metodologias para adequação do teste de tetrazólio das espécies listadas, realizando uma leitura exploratória, seletiva e analítica, e assim, compilando as indicações sugeridas por diversos autores em uma tabela. As palavras chaves utilizadas foram: Sementes florestais; Teste de vigor; Viabilidade e o nome científico das espécies pesquisadas.

\section{Resultados e Discussão}

Das 141 espécies do domínio fitogeográfico da Amazônia que foram pesquisadas, e que constam no documento do MAPA (Brasil, 2013), apenas para
36 dessas obtem-se trabalhos com metodologias para a aplicação adequada do teste de tetrazólio (Tabela 1).

Considerando o número reduzido de espécies com testes de tetrazólio observadas nesta pesquisa, constata-se que a tecnologia de sementes florestais nativas carece de estudos. Segundo Calvi e Ferraz (2014), em 2013 apenas 26\% das espécies de interesse comercial na Amazônia Ocidental possuíam normas para a avaliação da qualidade das sementes.

A utilização do teste de tetrazólio para determinação da qualidade fisiológica das sementes não é nova, foi desenvolvido por Delouche et al. 1976, mas a explicação pela falta de metodologias em espécies florestais nativas, se dá pelo comércio das mesmas até o momento ser ainda incipiente.

O teste de tetrazólio possui uma metodologia muito rápida e confiável, proporcionando resultados precisos da viabilidade e vigor das sementes, garantindo um ótimo desempenho no campo. Piña-Rodrigues e Santos (1988) afirmam que os resultados obtidos no teste de tetrazólio tendem a ser melhores que os obtidos no teste padrão de germinação, em função de não se verificar a presença de fungos e não se identificar a ocorrência de sementes dormentes.

A RAS (Brasil, 2009) já indica a utilização de testes rápidos em espécies que apresentam germinação lenta, a fim de minimizar prejuízos com relação ao tempo de avaliação de um lote de sementes.

No entanto, para a maioria das espécies florestais nativas, principalmente amazônicas, não há metodologias conhecidas e certificadas pela RAS para esse teste de controle de qualidade, devido principalmente não ser de interesse econômico e a fisiologia dessas espécies serem desconhecidas. Porém, a preocupação com a conservação genética, e o crescente mercado de sementes nativas para restauração florestal, poderá estimular pesquisas específicas em busca de normas para esses testes laboratoriais.

Oliveira e Ranal (2014) acreditam que o ato, em si, da legislação outorgar o aumento do número de espécies a serem utilizadas em projetos de reflorestamento ou reestruturação de áreas degradadas, em detrimento de indivíduos, dará auxílio para a formação de campos de produção de sementes nativas. 
Tabela 1- Espécies florestais nativas, do domínio fitogeográfico Amazônico, seus respectivos nomes científicos, família botânica, e indicações para a realização do teste de tetrazólio

\begin{tabular}{cl}
\hline Espécie & \multicolumn{1}{c}{ Indicação } \\
\hline & Pré-condicionar quatro repetições de 25 sementes em imersão na água destilada por \\
Anadenanthera peregrina (L.) Speg. & 24 horas a $25^{\circ} \mathrm{C}$, posteriormente realizar a retirada do tegumento das sementes e \\
(Fabaceae) & submergir os embriões em solução de $2,3,5$-trifenil cloreto de tetrazólio (pH 6,5$)$ na \\
& concentração de $0,1 \%$ por 24 horas a $30^{\circ} \mathrm{C}$, sendo sempre mantido nesse período no \\
& escuro (Pinho, Borges e Pontes, 2010). \\
\hline \hline
\end{tabular}

Astronium graveolens Jacq. (Anacardiaceae)

Terminalia corrugata (Ducke) Gere \& Boatwr (Combretaceae)

Byrsonima crassifolia (L.) Kunth
(Malpighiaceae)

(Malpighiaceae)

Bactris gasipaes Kunth (Arecaceae)

Bertholletia excelsa Bonpl. (Lecythidaceae)

Retirar a testa lenhosa das sementes, seccionar as amêndoas longitudinalmente e realizar o processo de embebição em água destilada por 20 horas, e após esse período submetê-las à imersão em solução de 2,3,5-trifenil cloreto de tetrazólio (pH 6,0 a 7,0) na concentração de $0,5 \%$, sendo mantidas em banho-maria a $45^{\circ} \mathrm{C}$ por 10 a 20 minutos (Reis et al., 1979).

Seccionar as sementes ao meio e imergir em solução de 2,3,5-trifenil cloreto de tetrazólio na concentração de $0,075 \%$, permanecendo no escuro, a $30^{\circ} \mathrm{C}$ por 24 horas. (Obs.: nesse estudo o teste de tetrazólio foi realizado somente nas sementes que ainda permanecia em estado de dureza após o teste de germinação) (Picolotto et al., 2013).

Imersão das sementes em solução de 2,3,5-trifenil cloreto de tetrazólio na concentração de 1,0\% por 24 horas. Para avaliação secciona-las longitudinalmente. (Obs.: nesse estudo o teste de tetrazólio foi realizado somente nas sementes que ainda permanecia em estado de dureza após o teste de germinação) (Azevedo, 2008).

Submeter os pirenos ao pré-condicionamento por imersão em um copo contendo $100 \mathrm{ml}$ de água, por 24 horas a $25^{\circ} \mathrm{C}$, com posterior quebra do endocarpo e extração das sementes, e seguido de hidratação das sementes por imersão em água $\left(24\right.$ horas a $\left.25^{\circ} \mathrm{C}\right)$, remoção dos tegumentos e extração dos embriões, utilizando quatro repetições de 25 embriões para o teste de tetrazólio. Imersão dos embriões em solução de 2,3,5-trifenil cloreto de tetrazólio na concentração de 1,0\%, por 3 horas a $40^{\circ} \mathrm{C}$. (Grzybowski et al., 2016).

Cabralea canjerana (Vell.) Mart. (Meliaceae)

Imersão das sementes em água destilada por 24 horas a $25^{\circ} \mathrm{C}$, com posterior seccionamento longitudinal através do centro do eixo embrionário, e imersão em solução de 2,3,5-trifenil cloreto de tetrazólio na concentração de $1,0 \%$ à $25^{\circ} \mathrm{C}$ por 2 a 3 horas (Grunennvaldt, Cantarelli e Salamoni, 2014).

Embebição das sementes em água destilada por 24 horas, estando acondicionadas em becker e mantidas em câmara de germinação tipo B.O.D na ausência de luz e sob temperatura constante de $25^{\circ} \mathrm{C}$, com posterior retirada do tegumento e imersão dos embriões em solução de 2,3,5-trifenil cloreto de tetrazólio na concentração de $0,5 \%$ (concentração mais eficaz) por 3 horas em câmera a $30^{\circ} \mathrm{C}$, na ausência de luz (Fré, 2010).

Seccionar longitudinalmente as sementes e submetê-las ao pré-condicionamento em água destilada por 24 horas a $25^{\circ} \mathrm{C}$, com posterior imersão em solução de 2,3,5-trifenil cloreto de tetrazólio na concentração de $0,1 \%$ por 6 horas na temperatura de $30^{\circ} \mathrm{C}$, sendo acondicionadas em copos plásticos, coberto com filme de plástico, na ausência de luz (Amoêdo, 2015). 
Continuação Tabela 1.

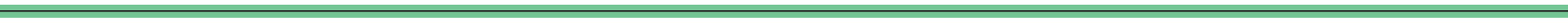

Casearia sylvestris Sw. (Salicaceae)

Submersão de cinco repetições de 10 sementes em água destilada por 6 horas a $30^{\circ} \mathrm{C}$, com posterior imersão em solução de 2,3,5-trifenil cloreto de tetrazólio na concentração de $0,5 \%$ sob a temperatura de $30^{\circ} \mathrm{C}$ durante 24 horas. Após esse período, seccionálas longitudinalmente para análise da coloração (Marcos Filho, 2005).

Colubrina glandulosa Perkins (Rhamnaceae)

Pré-umedecimento das sementes em papel toalha e acondicionamento das mesmas em câmara de germinação a $30^{\circ} \mathrm{C}$ por 5 horas, posteriormente cortá-las longitudinalmente e transversalmente, com a porção do cotilédone contendo o embrião, e por fim, imergir em solução de 2,3,5-trifenil cloreto de tetrazólio na concentração de $0,075 \%$ por 4 horas a $30^{\circ} \mathrm{C}$, na ausência de luz (Moraes et al., 2019).

Submeter quatro repetições de 25 sementes ao processo de embebição em água destilada

Copaifera langsdorffii Desf. (Fabaceae) por 120 horas, e posteriormente realizar a retirada do tegumento e imergir as sementes em solução de 2,3,5-trifenil cloreto de tetrazólio na concentração $0,2 \%$ por 10 horas a $30^{\circ} \mathrm{C}$, sendo acondicionado em recipiente escuro. Para a avaliação da coloração deve seccioná-las longitudinalmente (Vieira, 2015).

Submeter as sementes ao pré-condicionamento, onde serão embebidas entre papel de

Cupania vernalis Cambess. (Sapindaceae) germinação, previamente umedecido com água destilada (2,5 vezes a massa do papel) e acondicionados dentro de sacos plásticos, por 48 horas a $30^{\circ} \mathrm{C}$, em câmara de germinação, com posterior remoção total do tegumento, seguido de corte longitudinal da semente, e imersão em solução de 2,3,5-trifenil cloreto de tetrazólio na concentração de $0,05 \%$ por 2 horas a $40^{\circ} \mathrm{C}$ (Freitas, 2016).

Submeter quatro repetições de 25 sementes ao processo de embebição em água destilada por 12 horas, com posterior remoção do tegumento e imersão em solução de 2,3,5trifenil cloreto de tetrazólio na concentração de $0,2 \%$ por 12 horas a $30^{\circ} \mathrm{C}$, sendo acondicionado em recipiente escuro. Para a avaliação da coloração deve seccioná-las longitudinalmente (Vieira, 2015).

Dipteryx alata Vogel (Fabaceae)

Pré-condicionamento em embebição lenta das sementes, sendo acomodadas em três

Enterolobium schomburgkii (Benth.) Benth. (Fabaceae)

Eugenia stipitata McVaugh (Myrtaceae)

Genipa americana L. (Rubiaceae)

Hancornia speciosa Gomes (Apocynaceae)

Quatro repetições de 25 sementes. Seccionar as sementes com três cortes, sendo dois laterais e um na parte superior oposta ao eixo embrionário para a retirada do embrião, e imergir em solução de 2,3,5-trifenil cloreto de tetrazólio na concentração de $0,075 \%$ por 60 a 90 minutos, em B.O.D, a $40^{\circ} \mathrm{C}$ (Barros et al., 2010).

Imersão das sementes em água destilada por 24 horas, após esse período realizar a remoção do tegumento e imergir em solução de 2,3,5-trifenil cloreto de tetrazólio na concentração de $0,05 \%$ durante 15 horas em temperatura controlada de $30^{\circ} \mathrm{C}$ (Delfes et al., 2020). 
Continuação Tabela 1.

\begin{tabular}{|c|c|}
\hline $\begin{array}{l}\text { Handroanthus impetiginosus (Mart. ex } \\
\text { DC.) Mattos (Bignoniaceae) }\end{array}$ & $\begin{array}{l}\text { Quatro repetições de } 25 \text { sementes. Realizar a retirada da parte alada da semente e em } \\
\text { seguida submetê-las ao processo de embebição em água destilada por } 15 \text { horas a } 30^{\circ} \mathrm{C} \text {, } \\
\text { com posterior retirada do tegumento e imersão em solução } 2,3,5 \text {-trifenil cloreto de tetrazólio } \\
\text { nas concentrações de } 0,15 \text { ou } 0,30 \% \text { por } 6 \text { horas a } 30^{\circ} \mathrm{C} \text {, no escuro (Custodio et al., 2018). }\end{array}$ \\
\hline $\begin{array}{c}\text { Hevea brasiliensis (Willd. ex A.Juss.) } \\
\text { Müll.Arg. (Euphorbiaceae) }\end{array}$ & $\begin{array}{l}\text { Quatro repetições de } 50 \text { sementes (BRASIL, 2009). Retirar o tegumento com auxílio de } \\
\text { um martelo, seguido de embebição das sementes em papel toalha umedecido por } 18 \\
\text { horas, e após este período, imersão em solução de } 2,3,5 \text {-rifenil cloreto de tetrazólio na } \\
\text { concentração de } 0,5 \% \text { por } 2 \text { horas, em estufa a } 40^{\circ} \mathrm{C} \text { (Wetzel, Cícero e Ferreira, 1992). }\end{array}$ \\
\hline $\begin{array}{c}\text { Jacaratia spinosa (Aubl.) A.DC. } \\
\text { (Caricaceae) }\end{array}$ & $\begin{array}{l}\text { Submeter as sementes ao processo de embebição em água destilada, colocadas em } \\
\text { placas de petri e papéis filtro, por } 48 \text { horas, após esse período, imergir as sementes } \\
\text { em solução de } 2,3,5 \text {-trifenil cloreto de tetrazólio na concentração de } 1,0 \% \text {, por } 4 \\
\text { horas, em estufa a } 35^{\circ} \mathrm{C} \text {, sendo acondicionadas em recipientes de vidro cobertos com } \\
\text { papel alumínio (Rodrigues, 2016). }\end{array}$ \\
\hline
\end{tabular}

Submeter três repetições de 20 sementes ao processo de embebição em água destilada

Kielmeyera coriacea Mart. \& Zucc. (Calophyllaceae) por 24 horas em temperatura constante de $25^{\circ} \mathrm{C}$, e posteriormente colocar em contato com a solução 2,3,5-trifenil cloreto de tetrazólio na concentração de $0,5 \%$ por 24 horas em câmara de germinação à temperatura constante de $25^{\circ} \mathrm{C}$. Para a avalição deve seccionar as sementes ao meio e examinar a metade que contém o eixo embrionário (Ramos, 2011).

Extração dos embriões com posterior embebição em gerbox, utilizando papel mata borrão, por 72 horas, em câmera de germinação na temperatura de $25^{\circ} \mathrm{C}$, após esse Mauritia flexuosa L.f. (Arecaceae) período imergir os embriões em solução de 2,3,5-trifenil cloreto de tetrazólio na concentração de $0,5 \%$ por 4 horas sob temperatura de $30^{\circ} \mathrm{C}$ (Ribeiro et al., 2010; Rubio Neto et al., 2012; Spera, Cunha e Teixeira, 2001; Vitorino et al., 2017).

Mimosa caesalpiniifolia Benth. (Fabaceae)

Psidium acutangulum DC. (Myrtaceae)

Sapindus saponaria L. (Sapindaceae)

Schizolobium parahyba (Vell.) Blake (Fabaceae)
Submeter as sementes ao processo de embebição entre papel por 24 horas a $25^{\circ} \mathrm{C}$, com posterior remoção do tegumento e imersão das sementes em solução de 2,3,5-trifenil cloreto de tetrazólio na concentração de $0,075 \%$ à $35^{\circ} \mathrm{C}$ durante 1 hora (Silva, 2020).

Quatro repetições de 25 sementes. Submeter as sementes à escarificação mecânica utilizando lixa, e imergir em água destilada por 48 horas em temperatura ambiente, com posterior remoção do tegumento, e realizar a imersão dos embriões em $400 \mathrm{ml}$ de solução de 2,3,5-trifenil cloreto de tetrazólio ( $\mathrm{pH} 6,5)$ na concentração de $0,1 \%$ por 6 horas a $35^{\circ} \mathrm{C}$, mantidos em copos plásticos descartáveis no escuro. Para melhor avalição deve seccionar os embriões longitudinalmente (Costa et al., 2018).

Submeter as sementes ao processo de embebição em água destilada por 72 horas nas temperaturas de $30 \mathrm{ou} 40^{\circ} \mathrm{C}$, com posterior corte transversal nas sementes, a fim de expor o eixo embrionário sem causar danos em sua estrutura. Após o précondicionamento e preparo, imergir a metade das sementes que contém o eixo embrionário em solução de 2,3,5-trifenil cloreto de tetrazólio na concentração de $0,50 \%$, nas temperaturas de $30^{\circ} \mathrm{C}$ e $40^{\circ} \mathrm{C}$ durante três horas, na ausência de luz (Nascimento e Reis, 2014).

Imersão das sementes em ácido sulfúrico por 30 minutos e submissão ao préumedecimento por 24 horas a $30^{\circ} \mathrm{C}$, e em seguida imergir em solução de 2,3,5-trifenil cloreto de tetrazólio na concentração de $0,075 \%$ durante 4 horas, em câmara regulada a $30^{\circ} \mathrm{C}$, sendo acondicionadas em copos plásticos de $50 \mathrm{ml}$ cobertos com papel alumínio (Neves, 2018).

Quatro repetições de 20 sementes. O pré-condicionamento consiste em submeter às sementes escarificadas manualmente (com lixa $n^{\circ} 80$, na região oposta ao embrião) a 48 horas de embebição, entre papel de filtro umedecido, e acondicionado a $35^{\circ} \mathrm{C}$, com posterior retirada do tegumento, evitando-se danos ao embrião. Após este período são submetidas à solução de 2,3,5-trifenil cloreto de tetrazólio na concentração de $0,10 \%$ por 4 horas, a $35^{\circ} \mathrm{C}$, no escuro (Fogaça et al., 2011). 
Continuação Tabela 1.

\begin{tabular}{cl}
\hline & Escarificação mecânica das sementes utilizando lixa, e posterior imersão em água \\
Schizolobium parahyba var. amazonicum & destilada por 24 horas, à temperatura ambiente $\left(25^{\circ} \mathrm{C}\right)$. Após este período realizar a \\
(Huber ex Ducke) Barneby (Fabaceae) & remoção do tegumento e imergir os endospermas e embriões em solução de $2,3,5-$ \\
& trifenil cloreto de tetrazólio $(\mathrm{pH} 6,5)$ durante 3 horas a temperatura de $25^{\circ} \mathrm{C}$, na \\
& ausência de luz (Shimizu, 2009).
\end{tabular}

\begin{tabular}{|c|c|}
\hline $\begin{array}{l}\text { Senegalia polyphylla (DC.) Britton \& Rose } \\
\text { (Fabaceae) }\end{array}$ & $\begin{array}{l}\text { As sementes são pré-condicionadas em gerbox com água destilada por } 36 \text { horas na } \\
\text { câmara de germinação a } 30^{\circ} \mathrm{C} \text {. Após esse período, os tegumentos são removidos } \\
\text { manualmente e os embriões imersos em solução de } 2,3,5 \text {-trifenil cloreto de tetrazólio, } \\
\text { em gerbox protegidos da luz, na concentração de } 0,075 \% \text { por } 6 \text { horas a } 30^{\circ} \mathrm{C} \text { em câmara } \\
\text { de germinação (Lima e Cunha, 2019). }\end{array}$ \\
\hline
\end{tabular}

Hidratar as sementes entre papel germitest umedecido durante 14 horas. Depois de

Senna multijuga (Rich.) H.S. Irwin \& Barneby (Fabaceae) hidratadas, realizar a remoção dos tegumentos e endospermas, e imergir os embriões na solução de 2,3,5-trifenil cloreto de tetrazólio na concentração de $0,075 \%$ a $35^{\circ} \mathrm{C}$, permanecendo incubados por 5 horas em câmara de germinação (B.O.D), no escuro. Para a avaliação da coloração deve seccionar os embriões longitudinalmente (Ferreira, Davide e Motta, 2004).

Submeter três repetições de 20 sementes ao processo de embebição em água destilada por 24 horas em temperatura constante de $25^{\circ} \mathrm{C}$, e posteriormente colocar em contato com a solução 2,3,5-trifenil cloreto de tetrazólio na concentração de $0,5 \%$ por 24 horas em câmara de germinação à temperatura constante de $25^{\circ} \mathrm{C}$. Para a avalição deve seccionar as sementes ao meio e examinar a metade que contém o eixo embrionário (Ramos, 2011).

Submeter as sementes ao pré-condicionamento de punção seguida de embebição por 3 horas a $30^{\circ} \mathrm{C}$, com posterior retirada da parte alada e do tegumento. Após isso, submetê-las a 5 horas de imersão em solução de 2,3,5-trifenil cloreto de tetrazólio na concentração de $0,20 \%$ a $30^{\circ} \mathrm{C}$, no escuro (Silva et al., 2018).

\section{Conclusão}

Foi observado que existem poucos trabalhos científicos na literatura que abordam o estudo para utilização do teste de tetrazólio no controle da qualidade fisiológica das sementes em espécies florestais nativas, do domínio amazônico.

Ficou evidente a necessidade de pesquisas em espécies no geral, para proporcionar o enquadramento de metodologias na RAS (Regras para Análise de Sementes), a fim de obter a disposição essa tecnologia que fornece resultados rápidos e precisos, facilitando para o mercado sementeiro o controle de qualidade dos lotes de sementes a serem comercializados.

\section{Agradecimentos}

A FAPEMAT pela bolsa de iniciação científica á primeira autora.

\section{Literatura Citada}

AMOÊDO, S. C. 2015. Avaliação da viabilidade das sementes e amplitude térmica de germinação de duas espécies arbóreas amazônicas (Carapa guianensis Aubl. e Carapa surinamensis Miq.Meliaceae). Dissertação Mestrado. Manaus, AM, INPA. 62p.

AZEVEDO, M. I. R. 2008. Estrutura e restauração de cerradão em Palmas - TO e germinação de sementes de Buchenavia tomentosa Eichler, Hymenaea stigonocarpa Mart. ex Hayne, Guazuma ulmifolia Lam. e Enterolobium gummiferum (Mart.) J. F. Macbr. Tese Doutorado. Viçosa, MG, UFV. 118p.

BARROS, D. I. et al. 2010. Teste de tetrazólio em sementes de mangaba (Hancornia speciosa Gomes). Revista ACTA Tecnológica - Revista Científica (Brasil) 5(2):17-31. 
BORGES, M. de M. R. 2019. Metodologia do teste de tetrazólio para a avaliação da qualidade fisiológica de sementes de Enterolobium schomburgkii (Benth.) Benth. e Apuleia leiocarpa (Vogel) J. F. Macbr. Monografia (Agronomia). Belém, PA, UFRA. 32p.

BRASIL. MINISTÉRIO DA AGRICULTURA, PECUÁRIA E ABASTECIMENTO. 2009. Regras para análise de sementes. Ministério da Agricultura, Pecuária e Abastecimento, Secretaria de Defesa Agropecuária, Brasília, DF, Mapa/ ACS. 395p.

BRASIL. MINISTÉRIO DA AGRICULTURA, PECUÁRIA E ABASTECIMENTO. 2013. Instruções para análise de sementes de espécies florestais, de 17 de janeiro de 2013. Brasília, DF, MAPA. 98p.

CALVI, G. P. 2015. Armazenamento das sementes recalcitrantes de Eugenia stipitata McVaugh: aspectos tecnológicos e fisiológicos. Tese Doutorado. Manaus, AM, INPA. 89p.

CALVI, G. P.; FERRAZ, I. D. K. 2014. Levantamento das espécies florestais de interesse econômico e o cenário da produção de sementes e mudas na Amazônia Ocidental. ABRATES 24(2):24-75.

COSTA, M. A. et al. 2018. Seed quality evaluation by tetrazolium staining of Parkia multijuga Benth. Agricultural Sciences 8(5):577-586.

CUSTODIO, D. C. S. et al. 2018. Teste de tetrazólio em de Handroanthus impetiginosus (Mart. ex DC.) Mattos. In: Simpósio de Ciências Agrárias e Ambientais. Minas Gerais, 2018.

DELFES, L. da R. et al. 2020. Análise da qualidade de sementes florestais. In: Seminário de Iniciação Científica, 30. Florianópolis, SC, UDESC.

FERREIRA, R. A.; DAVIDE, A. C.; MOTTA, M. S. 2004. Vigor e viabilidade de sementes de Senna multijuga (Rich.) Irwin et. Barn. e Senna macranthera (Collad.) Irwin et. Barn., em um banco de sementes em solo de viveiro. Revista Brasileira de Sementes 26(1):24-31.

FERREIRA, S. A. N.; SADER, R. 1987. Avaliação da viabilidade de sementes de pupunha (Bactris gasipaes H.B.K.) pelo teste de tetrazólio. Revista Brasileira de Sementes 9(2):109-114.
FLORA DO BRASIL. 2020. Algas, Fungos e Plantas. 2020. Jardim Botânico do Rio de Janeiro. Disponível em:http://floradobrasil.jbrj.gov.br/ reflora/listaBrasil. Acesso em: 20 de abril de 2020.

FOGAÇA, C. A. 2003. Padronização do teste de tetrazólio para a avaliação da viabilidade de sementes de três espécies florestais. Dissertação Mestrado. Jaboticabal, SP, FCAV/UNESP. 49p.

FOGAÇA, C. A. et al. 2011. Teste de tetrazólio em sementes de Copaifera langsdorffii e Schizolobium parahyba. Floresta (Brasil) 41(4):895-904.

FOWLER, J. A. P.; MARTINS, E. G. 2001. Manejo de sementes de espécies florestais. 1. ed. Colombo, PR, Embrapa. 76p.

FRÉ, M. 2010. Avaliação da germinação, viabilidade e vigor de sementes de Calophyllum brasiliense Camb. Monografia (agronomia). Florianópolis, SC, UFSC. 60p.

FREITAS, L. C. N. 2016. Qualidade de sementes de Cupania vernalis (Cambess.) provenientes de remanescentes florestais da região oeste do Paraná. Dissertação Mestrado. Marechal Cândido Rondon, PR, UNIOESTE. 56p.

GRUNENNVALDT, R. L.; CANTARELLI, E. B.; SALAMONI, A. T. 2014. Armazenamento e viabilidade de sementes de Cabralea canjerana (Vell.) Mart. Science 5(1):98-105.

GRZYBOWSKI, C. R. de S. et al. 2016. Physiological potential and conservation of murici (Byrsonima crassifólia) seeds. Revista Brasileira de Fruticultura (Brasil) 39(5):(e-475).

LIMA, T. L.; CUNHA, M. do C. L. 2019. Viabilidade de sementes de Senegalia polyphylla (DC.) Britton \& Rose pelo teste do tetrazólio. Ciência Agrícola (Brasil) 17(3):23-30.

MARCOS FILHO, J. 2005. Fisiologia de sementes de plantas cultivadas. Piracicaba, SP, FEALQ. 495p.

MORAES, P. H. F. et al. 2019. Preparo da semente de colubrina para a execução do teste de tetrazólio. Revista Verde de Agroecologia e Desenvolvimento Sustentável (Brasil) 14(5):625-628.

NASCIMENTO, W. M. O.; REIS, A. H. A. 2014. Teste de tetrazólio para determinar a viabilidade 
em sementes de araçá-pera. In:Congresso Brasileiro de Fruticultura, 23. Mato Grosso, Cuiabá.

NEVES, M. I. R. da S. 2018. Caracterização, germinação de sementes e desenvolvimento pósseminal de Sapindus saponaria L. Tese Doutorado. Rio Largo, AL, UFAL. 87p.

OLIVEIRA, J. P. R.; RANAL, M. A. 2014. Sementes florestais brasileiras: início precário, presente inebriante e o futuro, promissor? Ciência Florestal 24(3):771-784.

PESKE, S. T. et al. 2006. Sementes: fundamentos científicos e tecnológicos. 2. ed. Pelotas, RS, Universidade Federal de Pelota. 454p.

PICOLOTTO, D. R. N. et al. 2013. Germinação de sementes de urucum em função de métodos de superação de dormência e temperaturas. Pesquisa Agropecuária Tropical (Brasil) 43(3):232-238.

PIÑA-RODRIGUES, F. C. M.; SANTOS, N. F. R. 1988. Teste de tetrazólio. In: Piña-Rodrigues, F. C. M. (coord.). 1988. Manual de análise de sementes florestais. Campinas, SP, Fundação Cargill. V. 1. 100p.

PINHO, D. S.; BORGES, E. E. de L.; PONTES, C. A. 2010. Avaliação da viabilidade e vigor de Anadenanthera peregrina (L.) Speg. submetidas ao envelhecimento acelerado e ao osmocondicionamento. Revista Árvore (Brasil) 34(3):425-434.

RAMOS, K. M. O. 2011. Avaliação da qualidade das sementes de Kielmeyera coriacea Mart. através da técnica de condutividade elétrica, teste de tetrazólio e de germinação. Dissertação Mestrado. Brasília, DF, UnB. 78p.

REIS, G. G. et al. 1979. Calibração do teste de tetrazólio em sementes de castanha-do-Brasil. Disponível em:https://www.embrapa.br/busca-depublicacoes/-/publicacao/381236/calibracao-doteste-de-tetrazolio-em-sementes-de-castanha-dobrasil. Acesso em: 26 de abril de 2020.

RIBEIRO, L. M. et al. 2010. Critérios para o teste de tetrazólio na estimativa do potencial germinativo em macaúba. Pesquisa Agropecuária Brasileira 45(4):361-368.
RODRIGUES, L. L. 2016. Frugivoria e dispersão de sementes pelo Jabuti-Piranga Chelonoidis carbonaria. Monografia (Ecologia). Rio Claro, SP, UNESP. 46p.

RUBIO NETO, A. et al. 2012. Effect of drying and soaking fruits and seeds on germination of macaw palm (Acrocomia aculeata [Jacq.] Loddiges ex Mart.). Acta Scientiarum Agronomy (Brasil) 34(2):179-185.

SANTOS, M. M.; ATAÍDE, G. da M.; PIRES, R. M. de O. 2019. Qualidade fisiológica de sementes de garapa (Apuleia leiocarpa) submetidas ao envelhecimento acelerado. Revista Biotemas (Brasil) 32(4):11-17.

SHIMIZU, E. S. C. 2009. Aspectos fisiológicos e bioquímicos relacionados à quebra de dormência física em sementes de paricá [Schizolobium parahyba var. amazonicum (Huber ex Ducker) Barneby]. Dissertação Mestrado. Belém, PA, UFRA. 46p.

SILVA, C. B. 2020. Padronização e otimização do teste de tetrazólio para sementes de Mimosa caesalpiniifolia (Benth.). Dissertação Mestrado. Maceió, AL, UFAL. 68p.

SILVA, L. M. 2003. Superação de dormência de diásporos de cajazeira (Spondias mombin L.). Dissertação Mestrado. Lavras, MG, UFLA. 64p.

SILVA, M. B. et al. 2018. Teste de tetrazólio em sementes de Tabebuia aurea (Silva Manso) Benth. \& Hook f. ex S. Moore. In: Simpósio de Ciências Agrárias e Ambientais. Minas Gerais, $\mathrm{BH}, 2018$.

SPERA, M. R. N.; CUNHA, R.; TEIXEIRA, J. B. 2001. Quebra de dormência, viabilidade e conservação de sementes de buriti (Mauritia Flexuosa). Pesquisa Agropecuária Brasileira 36(12):1567-1572.

VIEIRA, V. de O. 2015. Qualidade fisiológica e tratamento homeopático em sementes florestais provenientes da rede de sementes do Xingu, Mato Grosso, Brasil. Dissertação Mestrado. Alta Floresta, Mato Grosso, UNEMAT. 64p.

VITORINO, G. M. et al. 2017. Pré estabelecimento da remoção do embrião de $M$. flexuosa para 
a execução de teste de tetrazólio. WETZEL, M. M. V. S.; CÍCERO, S. M.; FERREIRA, In:Congresso Estadual de Iniciação Científica e Tecnológica do IF Goiano, 6. Goiás, Goiânia.

B. C S. 1992. Aplicação do teste de tetrazólio em sementes de seringueira. Revista Brasileira de Sementes 14(1):83-88. 